\title{
A PRESENÇA DA MÍDIA NA SOCIALIZAÇÃO CONTEMPORÂNEA DOS JOVENS: O CASO DO ANIME COMO CONVITE AO ESTUDO DA LÍNGUA JAPONESA
}

Nancy Naomi Uedal

Leiko Matsubara Morales ${ }^{2}$

RESUMO: O presente trabalho tem como objetivo explorar o fenômeno da difusão do animê pelos meios de comunicação por todo o mundo (por ex. a internet) e sua relação com o aumento no número de aprendizes da língua japonesa fora do Japão. Primeiramente apresentamos um panorama geral da cultura pop japonesa, em especial do animê e do mangá, no Japão e no mundo. Em seguida, exibimos os resultados de uma pesquisa quantitativa realizada com os aprendizes de língua japonesa da USP para então apresentar uma pesquisa qualitativa realizada com alguns aprendizes que tiveram o contato inicial com a língua japonesa por meio de animê. Por fim, discutimos algumas iniciativas recentes que visam a incentivar a associação da cultura pop com o ensino da língua japonesa no Brasil.

ABSTRACT: The present paper aims to explore the phenomenon of the diffusion of anime through worldwide communication (e.g., internet) and its relation to the

1. Bacharel em Relações Internacionais pelas Faculdades Integradas Rio Branco e graduanda em Ciências Sociais pela Universidade de São Paulo. E-mail: nancyueda@gmail.com.

2. Professora Assistente da Área de Lingua e Literatura Japonesa do Departamento de Letras Orientais e Doutoranda em Lingüística da Faculdade de Filosofia e Ciências Humanas da Universidade de São Paulo. E-mail: leikomm@usp.br. 
increase in the number of Japanese language learners outside Japan. Firstly, we present a general view of Japanese popular culture, especially anime and manga, in Japan and in the world. Then, the results of quantitative research carried out with Japanese language learners at USP are presented, followed by qualitative research carried out with some learners who have had initial contact with Japanese language through ani$m e$. Finally, some recent initiatives aimed to associate pop culture with teaching of Japanese language in Brazil are discussed.

PALAVRAS-CHAVE: animê, meios de comunicação, cultura pop japonesa, processo de socialização, ensino de língua japonesa.

KEYWORDS: anime, means of communication, Japanese pop culture, socialization process, teaching of Japanese language.

\section{A cultura pop japonesa como instrumento de divulgação da língua}

No início da primeira década do século XXI, as exportações de produtos culturais japoneses - tais como animê (desenhos animados japoneses), mangá (histórias em quadrinhos japonesas), videogames, música, livros, revistas, filmes, artesanato cresceram três vezes em relação à década anterior, passando de um faturamento de US\$ 5 bilhões em 1992 para US\$ 15 bilhões em 2002. Como exemplo do alcance dos produtos culturais japoneses no mundo, podemos mencionar que, em 2003, aproximadamente $60 \%$ da programação de desenhos animados exibidos nas televisões do mundo era composta por animê, sendo que em alguns países - como a Itália - essa percentagem era de $80 \%^{3}$

Nos últimos anos também foi possível observar uma forte presença da cultura japonesa no cinema mundial, seja por meio da exibição de animê (como 'A viagem de Chihiro' e ' $O$ castelo animado') seja pela influência dos animê sobre alguns sucessos de bilheteria produzidos por diretores americanos (como 'Kill Bill', de Quentin Tarantino, e a trilogia 'Matrix' dos irmãos Larry e Andy Wachowski)'.

Assim como esses diretores e outros executivos de Hollywood se tornaram fãs de séries de animê da década de 1960 (como 'Astro Boy' e 'Speed Racer'), hoje em dia milhares de crianças no mundo todo assistem a séries como 'Pokémon' e 'Dragon Ball's, e desenhos inspirados em animê.

A expansão dos produtos culturais japoneses no mundo foi acompanhada por um aumento no número de aprendizes da língua japonesa fora do território japonês, de

3. "FROM Niche to Mass: otaku bijinesu, sekai e hasshin", Newsweek (edição japonesa), 18/6/2003.

4. SATO, Cristiane A. Japop: O poder da cultura pop japonesa. São Paulo, NSP Hakkosha, 2007, p. 25.

5. "HARIUDDO wa Nihon ni muchû!", Newsweek (edição japonesa), 3/3/2004. 
981.407 em 1990 para mais de 2.356 .745 em 2003, conforme relatório da Fundação Japão (2003) ${ }^{6}$. Diversos países têm registrado um aumento expressivo no número de jovens que começam a estudar a língua japonesa devido a um interesse inicial por algum aspecto da cultura pop japonesa, como mangá, animê, música, videogame, filmes e moda?

Recentemente o governo japonês vem buscando formular diretrizes para uma diplomacia cultural que enfatize a cultura pop. De acordo com o professor e pesquisador Aoki Tamotsu, um dos formuladores do relatório " Bunka kôryû no heiwa kokka' Nihon no sôzô wo" ("Para a criação do Japão como uma nação pacífica de intercâmbio cultural") de $2005^{8}$, a razão básica pela qual o animê deve ser visto como um instrumento de diplomacia cultural é que ele serve de porta de entrada à cultura, sociedade, história e ao modus vivendi dos japoneses 9 . A despeito de outros entretenimentos de gêneros alternativos como sudoku, karaoke e mangá terem se popularizado ${ }^{10}$, o animê continua sendo destaque por se difundir em escala mundial.

\section{A difusão global do animê pelos meios de comunicação}

A difusão da televisão como meio de comunicação de massas nas três décadas após a Segunda Guerra Mundial incluiu o consumo dessa mídia como a segunda maior categoria de atividade depois do trabalho e a atividade predominante dentro dos lares ${ }^{11}$

No Japão, a televisão foi difundida em grande escala no início da década de 1960, alcançando 55\% dos lares em 1960 e $95 \%$ em 1964. Foi dentro desse contexto que, em 1963, estreou na televisão japonesa a série de animação 'Astroboy', de Osamu Tezuka. Como os custos de produção de episódios semanais não eram cobertos pelas taxas de transmissão recebidas das redes de TV, um dos principais meios de auxílio à produção de animê voltado para a televisão foi o licenciamento de personagens de desenhos para empresas diversas, como produtoras de alimentos e fabricantes de brinquedos $^{12}$.

6. JAPAN FOUNDATION. "Kaigai no nihongo kyôiku no genjô - nihongo kyôiku kikan chôsa 2003nen". Quanto ao número de aprendizes estrangeiros de japonês, o Brasil ocupa a décima posição no ranking, com $0,8 \%$ do total de estudantes de todo o mundo.

7. JAPAN FOUNDATION. "Kaigai no nihongo kyôiku no genjô - nihongo kyôiku kikan chôsa 2003nen". Disponivel em: http://www.jpf.go.jp/j/japan_j/oversea/surveyold.html.

8. "BUNKA kôryû no heiwa kokka' Nihon no sôzô wo". Bunka gaikô no suishin ni kansuru kondankai hôkokusho. 11-07-2005. Disponível em: http://www.kantei.go.jp/jp/singi/bunka/dai7/7siryoul.pdf.

9. AOKI, Tamotsu. "Sekai ni 'Nihon no anime sedai' wo sodate yo" Chûô kôron, no. 10, 2005, p. 114.

10. "Watashitachi wa minna nippon ni hamattemasu", Newsweek (edição japonesa), 5/4/2006.

11. CASTELLS, Manuel. A sociedade em rede. São Paulo: Paz e Terra, 1999, p. 416-419.

12. STEINBERG, Marc. "Immobile Sections and Trans-Series Movement: Astroboy and the Emergence of Anime", animation: an interdisciplinary journal, vol. 1, no. 2, 2006, pp. 190-206, p. 192-204. 
A exportação para o mundo consistiu noutra forma de gerar receita, como no caso de 'Astroboy' que apenas 8 meses após seu lançamento no Japão, foi o primeiro animê a ser exportado para os Estados Unidos. Outras regiões como Europa e América Latina começaram a importá-los na década de 1970. Nesse período inicial de exportação, um dos principais atrativos para a exibição nas redes de televisão de fora do Japão era seu baixo custo de aquisição. Em alguns países, o animê era editado para esconder a sua origem japonesa ${ }^{13}$.

No prefácio do livro Manga! Manga! The World of Japanese Comics, de 1983, Osamu Tezuka, criador de Astroboy, escreveu que, ao contrário do mangá que confundia os leitores ocidentais por ser lido da direita para a esquerda, o animê, que era dublado, desempenhou papel de "embaixador supremo da boa vontade do Japão, não só no Ocidente como também no Oriente Médio, na África, na América do Sul, no Sudeste Asiático, e mesmo na China", sendo que a porta de entrada dos animê nessas regiões era quase sempre pela $T^{14}$

Em alguns casos, no entanto, a tentativa de exportação de animê não obteve sucesso. Em 1978, a empresa japonesa Toei Animation estabeleceu seu primeiro escritório nos EUA para tentar promover seu animê no Ocidente. Apesar do sucesso de 'Space Battleship Yamato' (1978), houve a percepção por parte dos executivos da empresa em 1982 de que o animê não faria sucesso no mercado americano e isso levou à retirada do país ${ }^{15}$.

Com isso, tornou-se necessária a abertura de uma outra porta de entrada para o animê no território americano: as redes organizadas de fãs de animê. Sua ação foi possível graças ao surgimento de uma nova tecnologia de mídia - o videocassete desenvolvida pelos japoneses. Durante os anos 1980, esses aparelhos explodiram em todo o mundo e a sua difusão flexibilizou a utilização da mídia visual, possibilitando a gravação de programas de TV em horários oportunos ${ }^{16}$.

No Japão, a sua popularização permitiu que, mesmo não havendo exibição nos cinemas e TV, os OVAs (original video animation $)^{17}$. com conteúdo inédito, ficassem disponíveis ao público. Nos Estados Unidos, o videocassete foi lançado em 1975 e no ano seguinte começaram os encontros restritos de grupos de fãs de animê. Após a saída das empresas japonesas do mercado americano em 1982, não havia forças legais para desencorajar os fãs a copiar e distribuir fitas de animê entre eles. Esses fãs apro-

13. ENDÔ, Yutaka. Guro-baruka suru manga, anime, gêmu - saikôsei sareru 'Nihon bunka'. Tôkyô daigaku bungaku bu, Kôdô bunka gaku shakai gaku senshû katei, 2001, p. 24.

14. TEZUKA apud SCHODT, Frederik. Manga! Manga! The world of Japanese comics. New York: Kodansha International, 1983, p. 10.

15. LEONARD, Sean. "Progress against the law : Anime and fandom, with the key to the globalization of culture", International Journal of Cultural Studies, vol. 8, no. 3, 2005, pp. 281-305, p. 285-287.

16. CASTELLS, 1999, p. 99.

17. SATO, 2007, p. 36. 
veitaram a introdução do videocassete para compartilhar animê não-traduzido (ou $R A W$ em inglês) com outros fãs por meio de uma vasta rede internacional de fãs de animê que importavam e distribuíam fitas de videocassete de animê no período de 1976 a 1993. Por este meio, muitos fãs espalharam o conhecimento e entusiasmo pelo animê antes mesmo do uso da Internet ${ }^{18}$, como também tiveram contato com a língua japonesa no original.

A exibição e posterior sucesso da série em animê 'Cavaleiros do Zodíaco', em 1990, na Europa, geraram a primeira 'febre' internacional desse gênero. Além de um enredo facilmente assimilável que abordava uma mistura de mitologias, um outro fator que contribuiu para esse êxito foi a existência de um forte trabalho de merchandising patrocinado pela Bandai e que induzia os fãs a consumirem tudo o que fosse relacionado à série ${ }^{19}$

No final da década de 1990, outra série de animê causou sensação internacional. Inicialmente concebida como um software de videogame da Nintendo, a série 'Pokémon' estreou no Japão em 1997 e no ano seguinte passou a ser exibida em algumas partes dos Estados Unidos. No entanto, antes de ser efetivamente exibida, a série passou por algumas adaptações como a troca do nome dos personagens do japonês para o inglês e a escolha de uma música-tema nova em inglês ${ }^{20}$ Isso garantiu bons niveis de audiência para a série e a compra de direitos do animê por parte da Warner Brothers Pictures em 1999 para a distribuição nos Estados Unidos e no mundo ${ }^{21}$

Atingindo ampla divulgação, a série foi exibida por canais de televisão de 51 países $^{22}$.Como resultado de seu alcance estrondoso foram vendidos 28.890 .000 unidades de software de videogame no mundo e 2.400 .000 .000 unidades de card games no exterior, em diversos idiomas.

$\mathrm{Na}$ segunda metade da década de 1990, um novo sistema de comunicação eletrônica, chamado de multimídia, começou a ser formado a partir da fusão da mídia de massa personalizada com a comunicação mediada por computadores, o que passou a permitir a troca de arquivos de diversos formatos por meio da rede mundial de computadores ${ }^{23}$

Essa nova tecnologia logo passou a ser usada pelos fansubbers ${ }^{24}$ de animê a partir de 1998 para a prática do 'digisubbing; ou lançamento de seus fansubs como

18. LEONARD, 2005, p. 282-288.

19. SATO, 2007, p. 44.

20. Segundo ENDÔ (2001: 26), esse processo de 'americanização' pelo qual a série 'Pokémon' teve que passar é denominado tecnicamente como processo de 'localização' ('localizing' em inglês ou 'genchi $k a^{\prime}$ em japonês), que significa que um determinado produto cultural global é adaptado aos gostos e costumes dos mercados locais para garantir uma maior aceitação por parte do público local.

21. Idem, p. 98-99.

22. SATO, 2007, p. 99.

23. CASTELLS, 1999, p. 450.

24. 'Fansubbers' são indivíduos ou grupos de fãs que colocam legenda em filmes, desenhos ou novelas produzidas em outros paises para disponibilizá-los a outros fãs no idioma local. 'Fansubs' é o termo utilizado para referir-se aos filmes ou desenhos legendados por fâs. 
arquivos de vídeo para a distribuição na Internet ${ }^{25}$. Atualmente, esses arquivos alcançam milhares de pessoas por dia por meio de programas de compartilhamento de arquivos disponíveis na rede mundial de computadores, como BitTorrent. Normalmente as comunidades de fãs se organizam de tal modo que alguém, por pura diversão, grava espontaneamente a série exibida na TV japonesa, disponibilizando-a gratuitamente em poucos dias, acelerando ainda mais a propagação na língua original, como também na língua de chegada (do país receptor) por meio de softwares que possibilitam a inclusão de legendas feitas pelos próprios fãs ${ }^{26}$. Estima-se que em 1989, entre $5.000 \mathrm{e}$ 10.000 fãs assistiam ao animê gravado da TV japonesa e enviado aos EUA, com apenas alguns fãs adicionando legendas a eles. Hoje, quase todos os fansubs são transmitidos pela Internet e a quantidade de fãs é muito maior. Existem aproximadamente 500 grupos de fansub totalizando 2.500 membros e a base de fãs de animê explodiu para algo em torno de 300.000 e 500.000 entusiastas ativos ${ }^{27}$ Para a difusão da língua japonesa, é importante ressaltar o acesso ilimitado que os apreciadores tiveram a assistir ao animê no original, sem sofrer qualquer tipo de localização.

De modo resumido, o alcance global do animê pode ser observado no seguinte trecho:

"Nos Estados Unidos, heróis de desenhos animados de televisão de décadas passadas, como Astro Boy e Speed Racer, tornaram-se ícones. Heiki, a Menina dos Alpes e CandyCandy foram transmitidos na Europa. Chega-se a afirmar até mesmo que quase $90 \%$ da população da Espanha não abria mão de assistir a Mazinger $Z$. Alguns jogadores de futebol profissionais dizem ter começado a jogar com mais ardor depois de assistir à série Capitão Tsubasa. Poucos anos atrás o estrondoso sucesso de Sailor Moon na Alemanha também despertou grande interesse por outros animês no país. Na Ásia, Doraemon e Dragon Ball aparentemente são mais conhecidos que os filmes de animação da Disney. Animações do gênero cyberpunk que exploram o futuro próximo - inclusive Akira, de Otomo Katsuhiro; Ghost in Shell: Stand Alone Complex (O Fantasma na Máquina), de

\section{LEONARD, 2005, p. 301.}

26. Sobre este aspecto, não desmerecendo a oferta espontânea e gratuita que os fãs de animê iniciados na língua proporcionam aos usuários de fansubs que não entendem o japonês, há erros de traduções feitas de ouvido, como expressões em japonês shiken ni maniaukamoshirenai divulgado como "talvez seja maníaco por provas" no lugar de "talvez dê tempo para fazer a prova"; mizukara waza o amidasu "criou a técnica da água" em vez de "criou sua própria técnica". Ainda há aqueles que, não compreendendo o teor da formalidade de um diálogo entre professor e aluno, desconsideram totalmente a linguagem de tratamento, inserindo no final dos enunciados, marcas da oralidade e da linguagem de jovens, como "entendeu cara?". Sem contar que freqüentemente episódios de fundo cultural são descartados com uma explicação sem cerimônia: "esta é uma piada japonesa, você não precisa entender". Interessante notar que esses apontamentos foram trazidos pelos próprios alunos de japonês de nível avançado que se divertem com as traduções feitas ao pé do ouvido. Não se pode ignorar que tais fatos acontecem e o professor poderá aproveitar esses fatos para trabalhar aspectos culturais e lingüísticos como tópicos de aula, mediante um recurso novo e atraente para este público.

27. "Is Japanese Style Taking Over The World?", Business Week Online, 26/07/2004. 
Shiro Masamune; e Neon Genesis Evangelion - criaram um modelo que influenciou filmes como Matrix. Inspirado nos videogames Pokemon, o filme Pocket Monsters causou sensação nos Estados Unidos e se tornou um clássico. Todas as semanas são produzidos no Japão por volta de 50 a 60 novos animês, e vários deles são exportados"28

\section{O mangá no contexto da cultura pop japonesa}

Levando em consideração o fato de que a maioria das séries de animê tem sua origem em mangá, cabe mencionar brevemente o alcance dessa indústria de entretenimento no Japão.

Revistas semanais de mangá direcionados ao público masculino jovem começaram a ser lançadas a partir do final da década de 1950, como Shonen Magajin (1959), cujas vendas ultrapassaram 1,5 milhões de cópias em três anos, e Shonen Jump (1968), que registrou a venda de mais de 4 milhões de cópias em uma semana em dezembro de 1984; de mais de 6,5 milhões de cópias com o exemplar de 20 de dezembro de 1994 e hoje vende em média 3,4 milhões de exemplares ${ }^{29}$ Revistas de mangá voltadas ao público feminino jovem começaram a circular no mercado alguns anos depois ${ }^{30}$.

Até a metade da década de 1980, entretanto, o mangá era considerado um tipo de cultura vulgar. Editoras de prestígio como a Kodansha, que dependia da receita gerada pelas revistas de mangá para cobrir os custos da produção de seus periódicos acadêmicos e literários, não eram bem vistas devido à sua associação com o mangá. Essa situação começou a mudar no final da década de 1980 , graças à maior regulamentação governamental das categorias de mangá em dois grupos: 1) os que podiam ser considerados como parte da cultura nacional e 2) os que não se encaixavam nesse quesito e cuja produção deveria ser desencorajada ${ }^{31}$

A partir disso, tanto os mangá como os animê assumiram novas imagens que ampliaram seu público-alvo ${ }^{32}$. A indústria de mangá expandiu-se continuamente até o começo da década de 1990 quando havia 12 revistas com circulação superior a um milhão de exemplares e aproximadamente 50 revistas com a circulação entre 150.000 e um milhão ${ }^{33}$

28. YONEZAWA, Yoshihiro. "O culto mundial ao desenho animado japonês : Passado e presente do fenômeno", Nipponia, no. 27, 15 de dezembro de 2003, p. 5.

29. No Brasil, por exemplo, a revista semanal de maior tiragem é a Veja, que no final de 2006 registrou a tiragem de 1,2 milhão de exemplares.

30. ITO, Kinko. "A History of Manga in the Context of Japanese Culture and Society", The Journal of Popular Culture, vol. 38, no. 3, 2005, pp. 456-475, p. 468-470.

31. KINSELLA, Sharon. "Pro-establishment manga: pop-culture and the balance of power of Japan", Media, Culture \& Society, vol. 21, 1999, pp. 567-572, p. 567-568.

32. YONEZAWA, Yoshihiro. "O culto mundial ao desenho animado japonês : Passado e presente do fenômeno", Nipponia, no. 27, 15 de dezembro de 2003, pp. 4-16, p. 6.

33. ITO, 2005, p. 472. 
Em relação ao público-alvo das revistas de mangá, dados de 2002 mostravam a seguinte percentagem: $38 \%$ de revistas voltadas para os meninos; $37,7 \%$ para homens; $8,8 \%$ para meninas; $6,7 \%$ para mulheres; e $8,4 \%$ de revistas de outros gêneros. Levando em conta todo o mercado editorial japonês, o mangá totalizava quase $40 \%$ das publicações no país e arrecadava aproximadamente $22,5 \%$ das receitas no setor editoria ${ }^{34}$.

No final da década de 1990 começaram a surgir 'mangá cafés' ('manga kissa' em japonês), que disponibilizam exemplares de mangá de vários gêneros aos frequientadores, mediante o pagamento de uma taxa de acordo com o tempo de permanência. Atualmente, existem redes de 'mangá cafés' que ficam abertas 24 horas por dia e que se tornaram mais populares que os "karaokê box", onde as pessoas podem comer, beber e cantar karaokê com os amigos ${ }^{35}$

A sua influência no sistema educacional do Japão também se fez sentir, de modo que os mangá passaram a circular em sala de aula, como instrumento de estudo. Em 2002 foi implantada a matéria 'manga - visual pop culture' como atividade curricular de educação artística das primeiras e segundas séries do ginásio em escolas públicas ${ }^{36}$. Outra constatação do poder do mangá é a transformação do gênero em filmes e novelas de sucesso ${ }^{37}$

O grande sucesso do animê no mundo a partir do final da década de 1990 contribuiu para um aumento das publicações de mangá e até mesmo de revistas semanais de mangá, como Shonen Jump e Shojo Beat nos EUA; Banzai, Manga Power e Daisuki na Alemanha; Shonen na França; e Manga Mania na Suécia ${ }^{38}$. Nos EUA, por exemplo, alguns títulos de mangá, como Naruto, Negima e Fullmetal Alchemist, apareceram na lista semanal dos 150 livros mais vendidos no país em $2006^{39}$

Apesar da maioria das publicações de mangá no exterior ser precipuamente voltada para um público jovem masculino, nos últimos anos tem se verificado um aumento no número de leitoras jovens nesses países. Nos Estados Unidos, por exemplo, o primeiro 'shojo mangá' publicado em inglês, 'Fruits Basket' registrou o topo de vendas no setor de 'graphic novels' Acredita-se que atualmente quase $60 \%$ dos leitores

34. GRAVETT, Paul. Manga : Sixty Years of Japanese Comics. London: Laurence King Publishing Ltd, 2004, p. 13.

35. ITO, 2005, p. $472-473$.

36. SATO, 2007, p. 68.

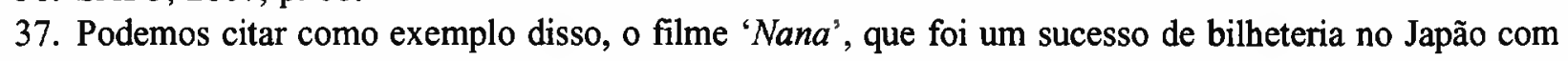
mais de 3 milhões de espectadores em 2005 e que é baseado no mangá homônimo de Yazawa Ai, e a novela 'Hana yori dango' exibida no final de 2005 e que é baseada no mangá homônimo de Kamio Yôko que detém o recorde de vendas da categoria 'shojo', com mais de 55 milhões de exemplares vendidos. Essa novela teve uma continuação em função do grande número de pedidos de parte de fãs japonesas da série ao fim da primeira fase televisiva. A segunda série 'Hana yori dango 2 (returns)' foi ao ar no início de 2007 com um roteiro que tinha como base cenas do mangá que as fâs mais gostariam de assistir na novela.

38. ASHBY, Janet. "Manga culture ignites craze in media markets overseas". The Japan Times, 14/08/ 2003.

39. "MANGÁS entre os livros mais vendidos dos EUA", UOL Teen, 13/09/2006. 
no país sejam mulheres jovens, o que torna o nicho do 'shojo mangá' o mais promissor do país. Diversos títulos de 'shojo' já foram (ou estão sendo) traduzidos para o inglês como 'Nana', 'Paradise kiss', 'Boys over flowers' ('Hana yori dango' em japonês) e 'Nodame cantabile'. Além disso, há um público de mulheres adultas que tem se interessado pelo gênero 'yaoi' que trata do homossexualismo masculino ${ }^{40}$.

\section{Pesquisa quantitativa com os estudantes de lingua japonesa da USP}

No início de 2006 foi realizada uma pesquisa quantitativa com os aprendizes de língua japonesa do Centro de Línguas (CL) e da graduação em letras japonês da Faculdade de Filosofia, Letras e Ciências Humanas da Universidade de São Paulo (FFLCHUSP) que serviu como ponto de partida para a parte empírica do presente estudo.

O questionário aplicado aos aprendizes foi elaborado pelos monitores sob a coordenação de um docente da área de japonês e teve como meta mapear o perfil do alunado e de suas necessidades, para definição do conteúdo programático de cursos extracurriculares. Ao longo das cinco páginas do questionário foram contemplados itens relacionados ao conhecimento e contato com a língua, experiências anteriores de aprendizado, motivação para o estudo da língua, exposição à mídia, entre outros.

O objetivo era levantar dados de aprendizes do $C L$, entretanto, notamos que poderia ser útil estabelecermos uma comparação com os alunos de graduação com habilitação em Japonês. Na graduação, foram selecionados alunos do primeiro e segundo anos de japonês, que cursavam as disciplinas Japonês I e III, respectivamente. Dos alunos de graduação, 88 concluíram as disciplinas referidas e 78 responderam ao questionário, correspondendo a $88,6 \%$ do total. Desses 88,49 eram alunos matriculados na habilitação em Japonês e cursaram a disciplina como obrigatória, enquanto 29 vieram de outras unidades da USP e a cursaram como optativa, contando créditos para a sua formação.

Dos alunos do CL, 57 aprendizes freqüentaram os cursos até o fim e destes, 51 responderam ao questionário, o que corresponde a $89,5 \%$ do total. No entanto, cabe ressaltar que dos 57 aprendizes matriculados no $\mathrm{CL}, 18$ aprendizes também freqüentaram a graduação, sendo este, portanto, um dos motivos para o estudo do japonês. É importante lembrar que os cursos do CL são pagos e não contam créditos.

Apresentaremos a seguir uma breve comparação do perfil geral dos aprendizes, separados em três grupos: Grupo 1 (49 estudantes de graduação com habilitação em japonês, como disciplinas obrigatórias); Grupo 2 (29 estudantes de graduação de outras unidades da USP, como disciplinas optativas) e Grupo 3 (57 aprendizes do CL, como curso extracurricular).

Em relação à sua distribuição por sexo, o Gráfico 1 mostra equilíbrio entre os três grupos.

40. "WATASHITACHI minna Nippon ni hamattemasu", Newsweek (edição japonesa), 5/4/2006. 


\section{Gráfico 1}

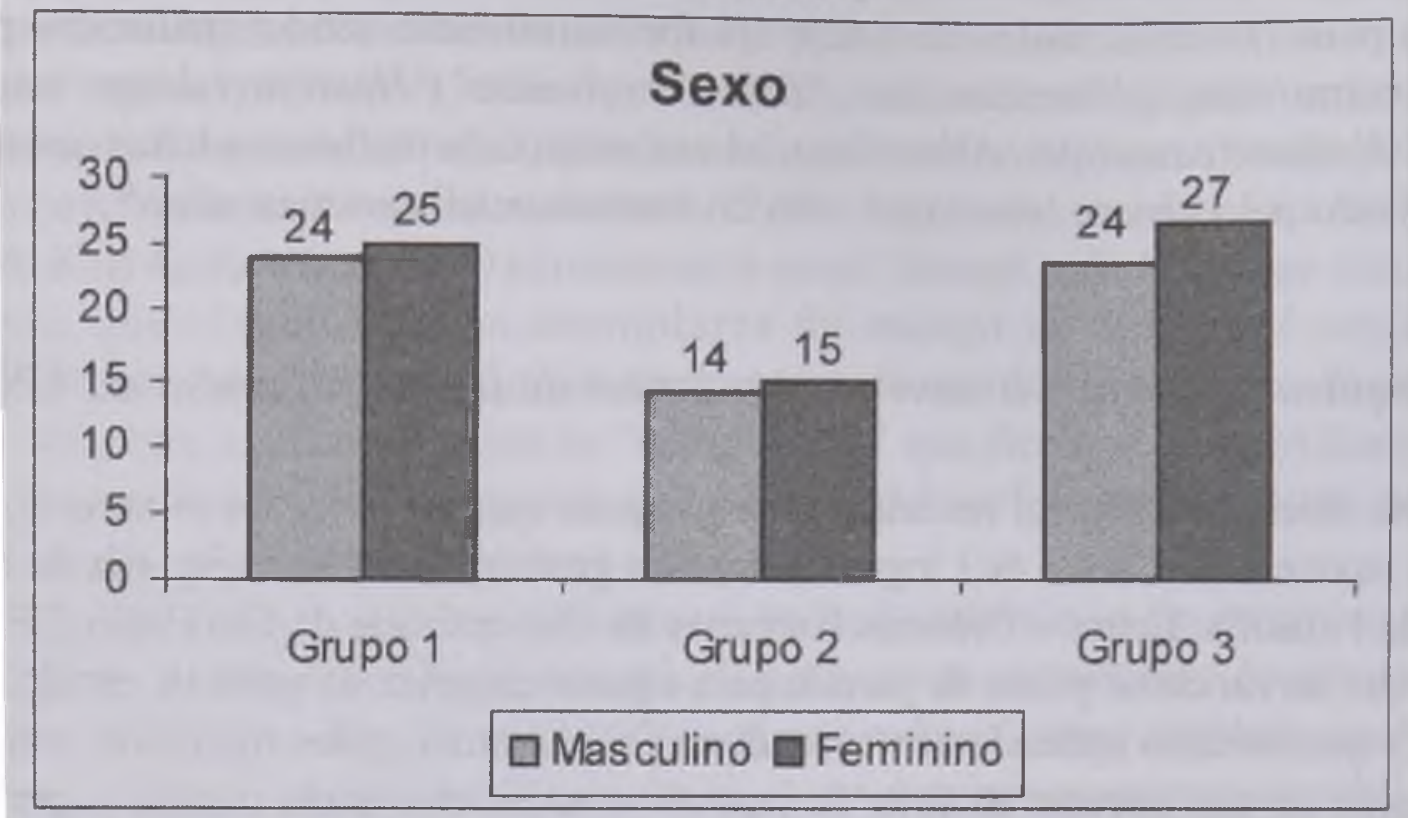

Fonte: Japonês - Centro de Línguas (FFLCH-USP)

No Gráfico 2, os aprendizes foram separados de acordo com o ano de nascimento, para conferir se houve coincidência com a época do 'boom' do animê no Brasil, que começou com a exibição de 'Cavaleiros do Zodíaco' em 1994. A maioria dos aprendizes dos três grupos nasceu entre os anos de 1988 e 1984 (tendo hoje entre $19 \mathrm{e}$ 23 anos) e pode ter sido exposta ao animê durante a infầncia. Logo a seguir estão os aprendizes entre os anos 1983 e 1979 e que durante a infância podem ter sido expostos aos 'tokusatsu' (séries japonesas com efeitos especiais, como por exemplo, 'Changeman', 'Jaspion', e 'Kamen Rider').

Gráfico 2

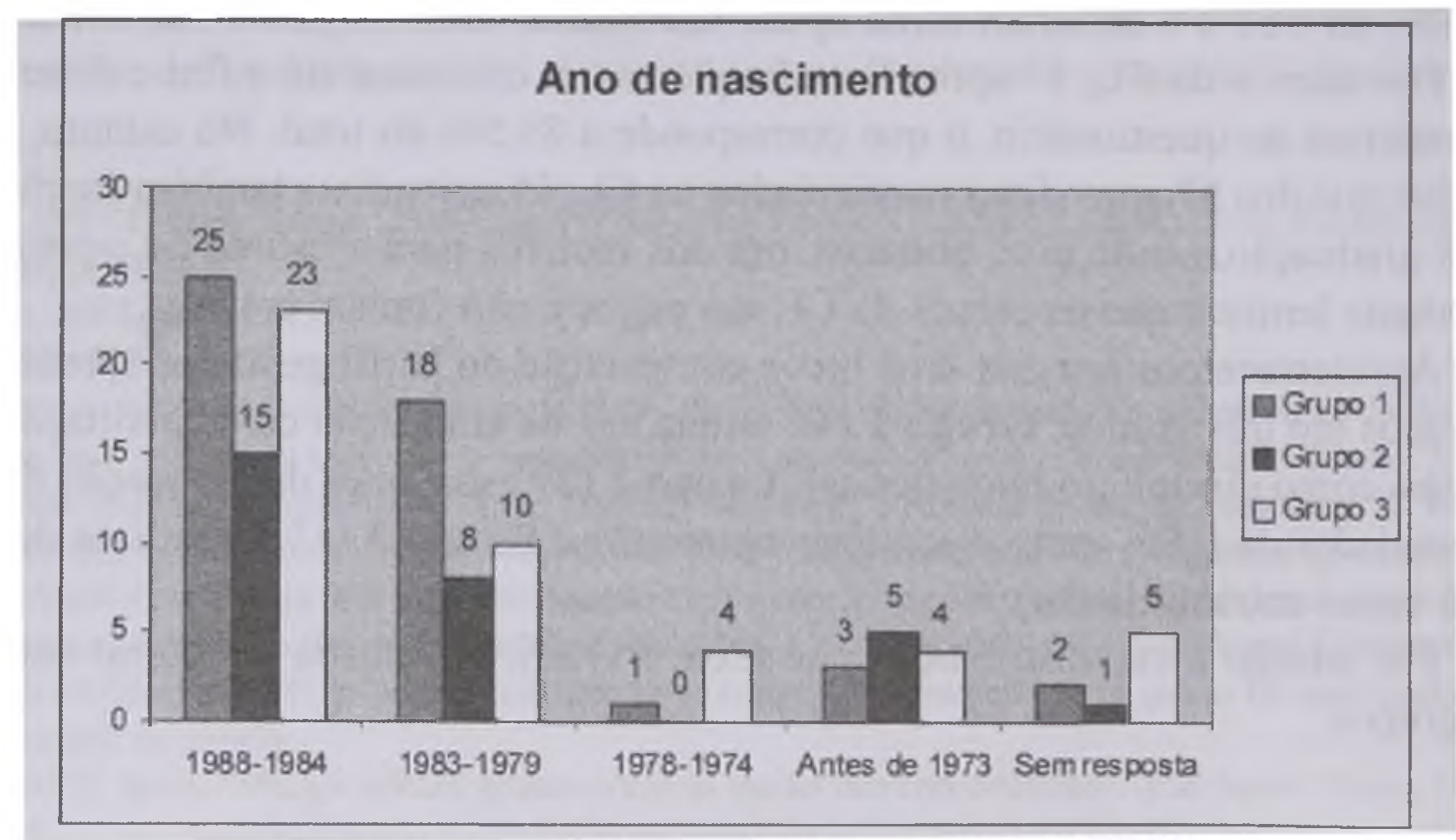

Fonte: Japonês - Centro de Linguas (FFLCH-USP) 
Em relação à ascendência, observamos no Gráfico 3 que no Grupo 1 os aprendizes são compostos majoritariamente por não-descendentes de japoneses, enquanto ocorre o contrário no Grupo 2, onde a maioria é descendente. Já no Grupo 3 verificamos um equilíbrio entre o número de aprendizes descendentes e não- descendentes. Há um aumento do interesse pela língua japonesa por parte dos não-descendentes que visam a trabalhar com aquela língua como um meio profissional, enquanto os descendentes escolhem a disciplina como optativa.

\section{Gráfico 3}

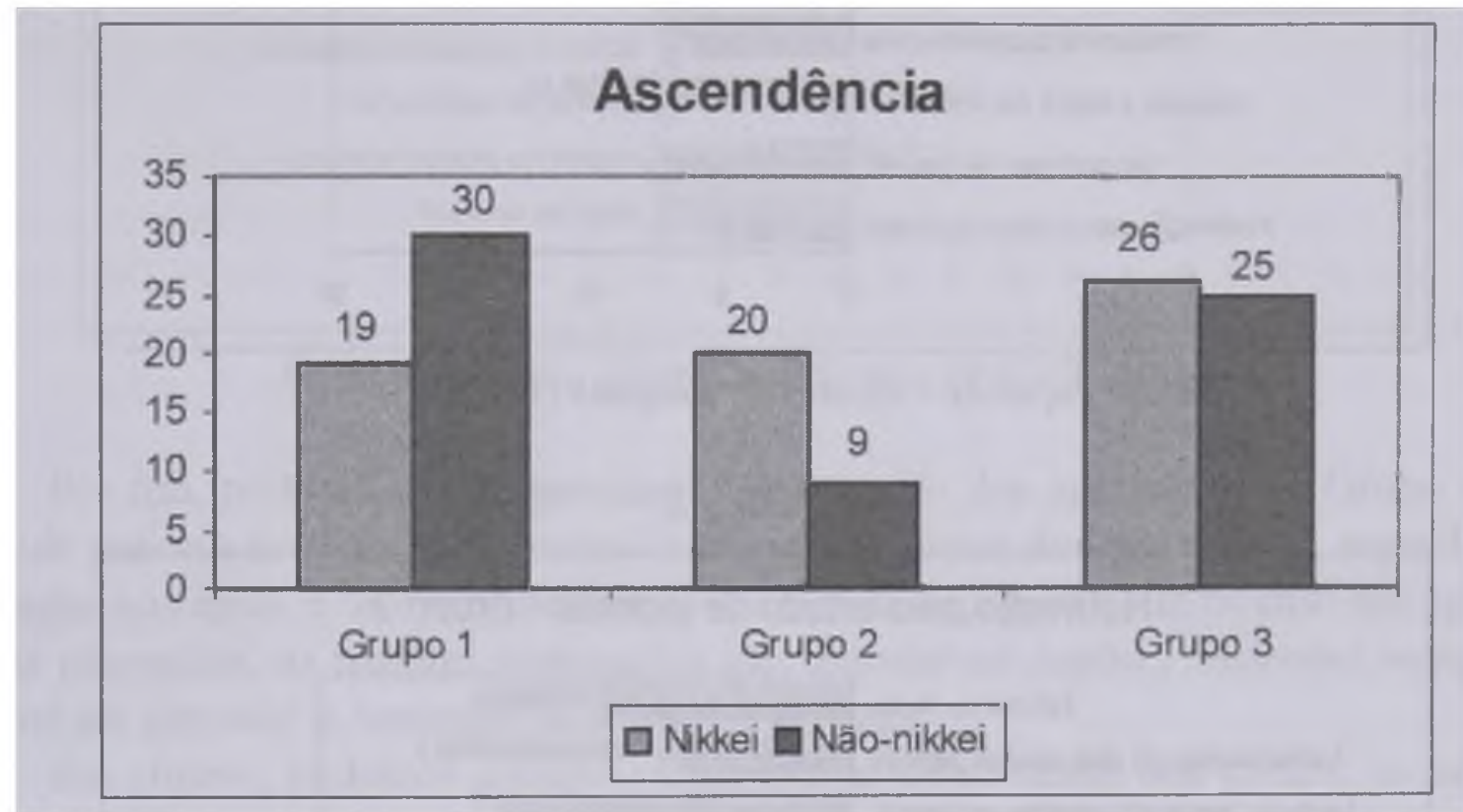

Fonte: Japonês - Centro de Linguas (FFLCH-USP)

Em relação ao quesito motivação, havia um item no questionário que pedia aos aprendizes que escolhessem três alternativas que mais os motivavam a estudar o japonês. Somando o total de vezes que cada alternativa foi mencionada, obtivemos os dados motivacionais de cada grupo. Consideramos conveniente dividir dentro de cada grupo os aprendizes entre descendente e não-descendente já que uma das alternativas bastante citadas ("conhecer a lingua dos ancestrais") só pôde ser mencionada pelos descendentes.

No Gráfico 4, temos a motivação do Grupo 1. Podemos notar que os aprendizes descendentes assinalaram com maior freqüência 'aprimoramento do nivel atual de japonês' e 'conhecer a língua dos ancestrais', enquanto que os não-descendente marcaram 'estudar no Japão', 'ler livros, jornais elou revistas em japonês' e 'ser tradutor/intérprete de japonês'. 

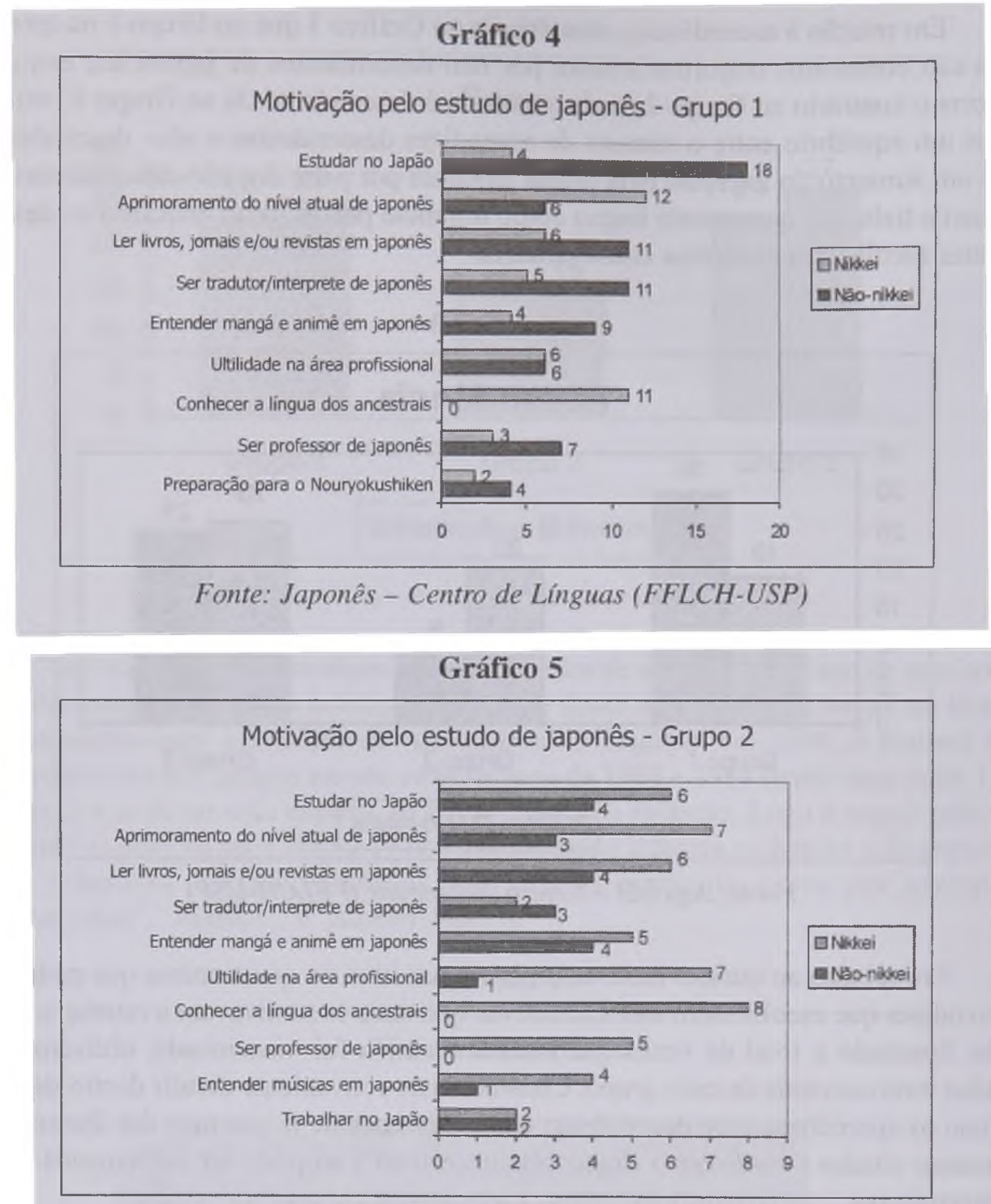

Fonte: Japonês - Centro de Línguas (FFLCH-USP)

O Gráfico 5 mostra as motivações dos descendentes do Grupo 2: 'conhecer a língua dos ancestrais', 'aprimoramento do nível atual de japonês' e 'utilidade na área profissional'. Os não-descendentes, por sua vez, marcaram 'estudar no Japão', 'ler livros, jornais elou revistas em japonês' e 'entender animê e mangá em japonês'. 


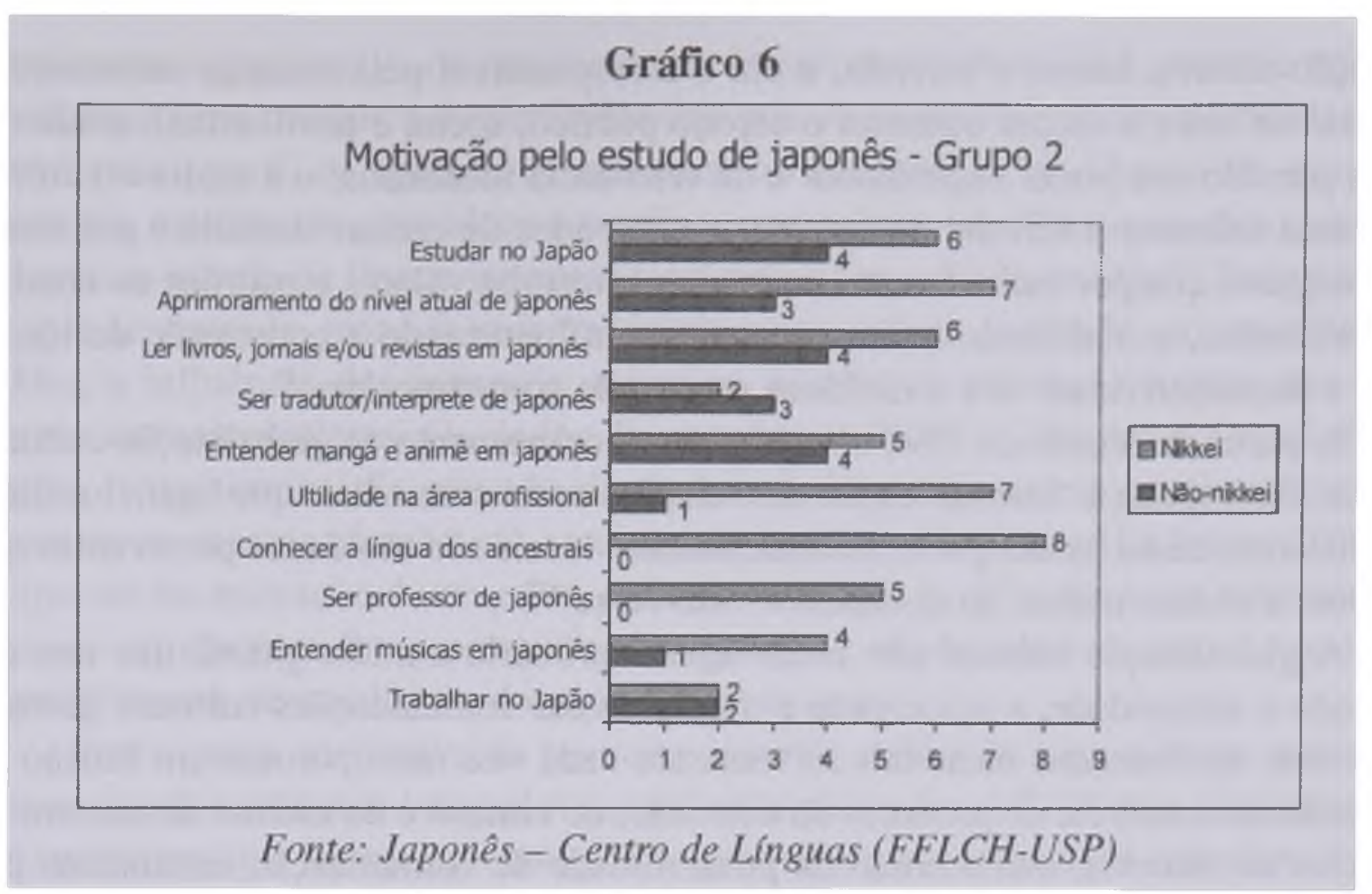

Por fim, no Gráfico 6 observamos a motivação dos aprendizes do Grupo 3. A grande maioria dos nikkei assinalou 'conhecer a língua dos ancestrais', seguida de 'estudar no Japão' e 'aprimoramento do nível atual de japonês'. Já no caso dos aprendizes não-nikkei, as maiores motivações são 'estudar no Japão', 'entender mangá e animê em japonês' e 'entender músicas em japonês'.

Em síntese, pudemos constatar que, independentemente dos cursos, os nikkei gostariam de 'conhecer a língua dos ancestrais' e 'aprimorar o nível atual de japonês', revelando interesse pela cultura ancestral e possuir algum conhecimento da língua no momento da escolha do curso de japonês. Já para os não-nikkei, a alternativa em comum dentre as três mais citadas em cada grupo foi 'estudar no Japão', sendo que somente o Grupo 3 mencionou como fator motivacional entender itens da cultura pop japonesa (mangá, animê e músicas) na sua língua original, o que mostra a influência do mangá e animê como um dos principais fatores motivacionais.

De posse desses dados, entendemos que seria significativo focalizar a parte qualitativa dos não-nikkei do Grupo 3.

\section{O processo de socialização contemporâneo}

Até a década de 1960, a família e a escola eram tidas como as principais instituições para a formação de identidade e socialização dos indivíduos. No entanto, a partir da década de 1970, com o surgimento de um mercado difusor de cultura de massa principalmente por meio da televisão no Brasil, começou a haver uma mudança no processo de socialização contemporâneo, que passou a incluir a mídia como uma terceira instância socializadora. De modo resumido, a família constitui o espaço de iden- 
tificação afetiva, moral e privado, e ela é a responsável pela herança econômica e cultural de base; a escola constitui o espaço público, social e profissional, ainda que tenha perdido seu poder organizador e de referência identitária; e a mídia ou cultura de massa refere-se à difusão de imagens e conteúdos de caráter simbólico por meios tecnológicos que por meio de entretenimento transmite valores e padrões de conduta diversificados, socializando muitas gerações e influenciando a construção da identidade e da subjetividade dos indivíduos no mundo contemporâneo ${ }^{41}$

A partir da década de 1990 observamos o aceleramento da globalização cultural, no que diz respeito à "intensificação das relações sociais mundiais que ligam localidades distantes de tal modo que os acontecimentos locais são moldados por eventos que ocorrem a muitas milhas de distância e vice-versa"42

A globalização cultural tem como agente primário a mídia global, que tem aumentado a intensidade, a velocidade e o volume das comunicações culturais globais. Com isso, as fronteiras nacionais se tornaram cada vez mais porosas em função da expansão no comércio de produtos da televisão, do cinema e do rádio e do número de usuários da Internet, assim como da possibilidade de comunicação instantânea por meio da difusão acelerada das tecnologias de rádio, televisão e Internet. Dentro desse contexto dinâmico, toma-se cada vez mais difícil para os órgãos nacionais controlarem as informações que circulam dentro de suas fronteiras geográficas ${ }^{43}$.

O predomínio da mídia de massa, como música popular, moda, televisão, Internet e videogames, nas vidas dos jovens em sociedades industrializadas faz com que esta constitua em muitos casos sua fonte cultural primária ${ }^{44}$.

\section{A influência do animê na socialização dos informantes selecionados}

Embora reconheçamos a interdependência entre as três instâncias socializadoras (família, escola e mídia) no processo de construção de identidade dos indivíduos no mundo contemporâneo, o estudo restringirá a análise à instância midiática, pois o objetivo é conferir como ocorreu o contato inicial com a língua japonesa e como isso evoluiu para um interesse e atitude para a escolha do curso de japonês.

$\mathrm{O}$ aumento no número de aprendizes da língua sem ascendência nipônica parece acompanhar uma tendência global recente, manifesta inclusive onde não há um

41. SETTON, Maria da Graça Jacintho."A particularidade do processo de socialização contemporâneo", Tempo Social, v. 17, n. 2, novembro de 2005, pp. 335-350, p. 345-347.

42. GIDDENS apud HOOGVELT, Ankie. Globalization and the postcolonial world : the new political economy of development. Baltimore: The Johns Hopkins University Press, 2001, p. 125.

43. HELD, David \& MCGREW, Anthony. Prós e Contras da Globalização. Rio de Janeiro: Jorge Zahar, 2001, p. $45-46$.

44. MASTRONARDI, Maria. "Adolescence and media", Journal of language and social psychology, vol. 22, no. 1, March 2003, pp. 83-93, p. 83. 
contingente significativo de descendentes de japoneses. Nos EUA, por exemplo, foi constatada uma mudança de perfil dos aprendizes de japonês. Se na década de 1980 prevalecia o perfil de aprendizes que eram influenciados pelo ' boom' da economia japonesa, atualmente, prevalece o perfil de aprendizes que têm como maior motivação para o estudo da língua japonesa o interesse por animê e mangáa ${ }^{45}$. Ressalvandose que se trata de espaços universitários, ainda assim, é grande, no caso de nãonikkei, a influência dos mangá e animê na escolha da carreira universitária ou de cursos extracurriculares. Os dados da enquête de 2005 da Aliança Cultural BrasilJapão, maior instituição privada de ensino de língua japonesa no Brasil também apontam na mesma direção: do contingente de 1300 alunos matriculados, $70 \%$ participaram na aplicação de enquête, e destes, cerca de 6 a $8 \%$ disseram estar motivados no estudo para ler e compreender mangá e animê, embora não tivesse sido especificada a descendência dos que responderam.

Para a parte qualitativa da pesquisa, dos não-nikkei do Grupo 3 que mencionaram ter motivações para 'entender mangá e animê em japonês' foram separados quatro aprendizes que tiveram contato prévio com a língua por meio de animê ou mangá. Desses quatro, destacamos três que concluíram o curso do CL: uma aluna (nomeada de Informante 1) e dois alunos (Informante 2 e Informante 3).

A parte empírica teve como foco o animê exibido na TV (aberta ou a cabo), por estar presente em $91,4 \%$ dos domicílios brasileiros (contra $18,6 \%$ de computadores no país) ${ }^{46}$.

No Brasil, alguns dos primeiros animê exibidos na TV aberta foram Speed Racer, A Princesa e o Cavaleiro na década de 1970 e Patrulha Estelar, na década de $1980^{47}$ Porém, o 'boom' do animê ocorreu em meados da década de 1990, com a exibição de desenhos como Cavaleiros do Zodíaco, Sailor Moon, Samurai Warrions, Shurato e Os Supercampeões. E a partir do ano 2000, com o sucesso de desenhos como Pokémon e DragonBall $Z$, o animê explodiu em todo o país ${ }^{48}$.

Além da programação disponível na TV aberta, a década de 1990 presenciou o desenvolvimento de tecnologias de TV a cabo que aumentaram as opções do telespectador no mundo inteiro ${ }^{49}$. No Brasil podemos citar a Cartoon Network, que

45. SCHODT, Frederik. "Manga fans take their Japanese to another level", The Japan Times, 02/05/2006 e MANION, Annie. Discovering Japan: anime and learning Japanese culture. Thesis Presented to the Faculty of Southern California. August 2005.

46. "VENDA de PCs no país deve encostar na de TVs neste ano", Folha de São Paulo, 3 de fevereiro de 2007.

47. Antes da chegada dos animê no Brasil, foi exibida na tevê brasileira pela Record em 1964 a série japonesa de tokusatsu 'National Kid', a qual cativou o público infantil e tornou-se muito popular no pais, sendo reprisada nos anos seguintes até que seus filmes foram perdidos em 1970 em função de vários incêndios que atingiram as instalações da Record. Outros tokusatsu como 'Changeman' e ' $O$ Fantástico Jaspion' foram exibidos na década de 1980 pela extinta TV Manchete. (SATO, 2007, p. 318-320).

48. "ESPECIAL Japão: 40 anos na TV", Revista Kidmais, ano 2, no. 22, junho de 2000.

49. CASTELLS, 1999, p. 423. 
exibia (e ainda exibe) animê editado nos EUA, e o extinto canal Locomotion, que em 2005 cedeu lugar para o canal Animax da Sony que exibe 24 horas de animê por dia.

Dos três entrevistados, somente a Informante 1 não possuía nenhum conhecimento da cultura japonesa antes de começar a se interessar por animê. O Informante 2 teve contato com uma família de japoneses desde a infância e o Informante 3, pela prática de kung fu iniciada aos 6 anos, passou a se interessar por filmes de artes marciais, ninja e samurai, sem, no entanto, conseguir distinguir nessa fase o que vinha do Japão ou de outros países da Ásia.

No início, os três informantes assistiam aos desenhos animados na TV aberta, sem identificar a sua origem. Somente a Informante $I$ teve contato com animê originais na infância por meio de TV a cabo e fitas de vídeos alugadas por sua mãe:

“Eu lembro que minha mãe assistiu 'Totoro' na HBO, ai ela amou o Totoro, ela assistiu primeiro que eu e falou, 'olha que desenho bonitinho' mas eu era muito pequenininha. Eu lembro que o desenho era muito fofo e eu fiquei com a música 'Tonari no tottoro... na cabeça quando era pequena. Aí... mas a minha mãe alugava muita fita de vídeo de desenho pra mim e alugava um desenho japonês, eu lembro que eu tinha uns 4 anos e chamava 'Ninki Momo' que no Brasil ficou conhecido como a 'Princesa Gigi' e eu amava aquele desenho, simplesmente amava e sempre assistia"

A descoberta de que o animê era originário do Japão ocorreu ao acaso, já na fase adolescente dos entrevistados. No caso da Informante 1 foi por meio da revista 'Animedô' com informações sobre animê, incluindo a série 'Pokémon' No caso do Informante 2, a descoberta ocorreu por meio do canal Cartoon Network da TV a cabo, onde eram exibidos animê como 'Evangelion' e 'Samurai $X$ ', este último ambientado no passado histórico do Japão (por volta do final do século XIX).

Uma vez identificada a origem do animê, a percepção dos informantes começa a ganhar contornos mais nítidos.

Informante 1: "[Na adolescência] eu comecei a desenhar conforme o animê e já vi que tinha um traço diferente, ai eu comecei a notar mais traços (...) fui percebendo a estética, fui percebendo um pouquinho do conteúdo, que é meio diferente, assim (...) Mostra mais realmente o humano... não fica muito... nos desenhos americanos tem muita fábula assim... cachorro indo atrás do gato, gato indo atrás do passarinho, ou você vê muito superherói... superherói de anos, que não acaba.. Aí no animê você tem sempre histórias diferentes, assim, agora tá tudo muito igual, mas tem histórias novas, diferentes, dinâmicas que mostram a vida dos adolescentes na escola, mostra... sei lá, uma pessoa normal ganhando poderes, assim também, mas ela ainda quer ser uma pessoa normal. Então eu fui notando umas coisas assim, $e$ ainda estou notando" 
Informante 2: "Eu comecei a ver que os desenhos japoneses são geralmente mais densos que os americanos. Além de ter um look' totalmente diferente, tem mais conteúdo geralmente. Eu acho que os japoneses são mais legais porque desenham a pessoa de um jeito normal. Os americanos quando desenham um superherói eles desenham o cara mais 'bombadão' que existe (...) Os japoneses não ficam naquele 'oh, nossa o cara é forte, precisa ser forte para ser o herói' Desenham mais simples, uma pessoa mais parecida com uma pessoa mesmo e mesmo assim ela é o herói da trama. E nem sempre na trama é preciso você ser forte (...) Nos animês você vê que até o heroizinho chora. É mais próximo da realidade, é mais humano. Eu acho que o americano é mais uma realidade diferente, eles querem passar que o herói deles é 'o herói' e o japonês passa que o herói é 'gente""

Atualmente, a popularidade do animê tem contribuído para a divulgação da música pop na língua original ${ }^{50}$, já que geralmente os desenhos vêm acompanhados por músicas-tema em japonês. Desde o advento do canal Animax na TV paga, também é possível assistir a clipes de artistas japoneses nos intervalos entre um e outro animê (aproximadamente a cada 30 minutos). Notamos que os entrevistados foram expostos à língua original e apreciavam músicas na língua japonesa, mesmo sem compreender as letras no início. No caso do Informante 2, a primeira percepção da escrita ideográfica ocorreu durante a exibição da música de encerramento de um animê.

Quanto ao mangá, este já circulava comercialmente desde a década de $1950^{51}$ em livrarias de imigrantes. No entanto, estas livrarias começaram a desaparecer a partir da década de 1980, em conseqüência da redução de leitores em japonês. Como afirma Sato, os quadrinhos japoneses foram valorizados primeiro na Europa e nos Estados Unidos, para depois atrair leitores descendentes de japoneses e chamar a atenção de leitores não-descendentes ${ }^{52}$ Assim como o animê, alguns mangá também já haviam sido traduzidos ao português nas décadas de 1980 e 1990, como 'Lobo Solitário' pela Editora Cenibra e 'Akira' pela Editora Globo. No entanto, foi o sucesso do animê exibido pela TV aberta que contribuiu para o 'boom' dos mangá a partir de $2001 \mathrm{com}$ o lançamento de títulos como 'Dragon Ball Z' e 'Cavaleiros do Zodíaco', pela Editora Conrad, e 'Samurai X', 'Sakura Card Captors' e 'Guerreiras Mágicas de Rayearth', pela Editora $\mathrm{JBC}^{53}$. Atualmente, a JBC e a Conrad, as principais editoras de mangá no Brasil, colocam nas bancas aproximadamente um milhão de exemplares por mês ${ }^{54}$.

50. SATO, 2007, p. 39.

51. Antes mesmo da comercialização dos mangá, os imigrantes costumavam fazer rodizios para a leitura de mangá e algumas escolas de língua japonesa chegavam a ter salas de leituras.

52. Idem, p. 66.

53. "INVASÃO de mangás", Made in Japan, no. 45, ano 4, junho de 2001.

54. "NO mundo da fantasia" Veja, 29 de janeiro de 2003. 
Ainda recentemente, as editoras lançaram cursos de japonês com comentários gramaticais baseados em enunciados retirados de mangá.

Os três entrevistados adquiriram ao menos um título de mangá. No caso dos Informantes 2 e 3, o único mangá comprado foi 'Samurai $X$ ' Já a Informante 1 coleciona: 'Sakuracard Captors', 'Guerreiras mágicas de Rayearth', 'Samurai $X$ ', 'Chobits', 'Evangelion', 'Inuyasha', 'Fruits Basket', 'Fushigi Yûgi', 'Tsubasa Cronicles' e 'Peach Girl'

Durante a entrevista, tentamos verificar se houve alguma ligação entre gostar de animê e o interesse pelo estudo da língua. No caso dos Informantes 1 e 3, o animê teve um papel fundamental:

Informante 1: "Depois de Pokémon, de descobrir os animês e os mangás eu percebi que gostava muito muito muito das coisas japonesas. Aí depois eu descobri que existe um Japão por trás dessas coisas, eu descobri que tem toda uma história, toda uma cultura e eu comecei a ir atrás. Eu falei, 'nossa, então vamos aprender o japonês também!' Mas eu só fui aprender o japonês na faculdade. (...) Foi porque eu gostava mesmo, foi amor"

Informante 3: "Não sabia nada de japonês antes de entrar na USP (...) mas gostava muito da cultura, eu assistia e assisto muito desenho animado japonês, leio muito a respeito da cultura oriental; eu não tenho tanta vontade de ir para o Japão, mas a cultura deles me interessa muito"

O Informante 2 não soube precisar se foi o animê ou o contato com uma família de descendentes de japoneses ou porque havia gostado de garotas descendentes. Em nenhum dos casos, as pessoas envolvidas falavam o japonês.

\section{Políticas culturais e eventos de incentivo ao estudo da língua}

Diversos órgãos governamentais e centros de apoio ao professorado interpretam o boom da cultura pop japonesa como uma estratégia de promoção do estudo da língua.

O Centro Brasileiro de Língua Japonesa ${ }^{55}$ (CBLJ) vem desde 2003 organizando o Nihongo Matsuri (Festival de Língua Japonesa), quando faz a premiação do concurso de desenhos, recebendo mais de mil visitantes entre professores, alunos e interessados em geral $^{56}$ Por causa da repercussão, o evento continua acontecendo anualmente

55. Entidade civil, sem fins lucrativos, fundada em 20 de fevereiro de 1988, que visa promover cursos e seminários para os professores, como também organizar eventos ligados ao ensino da língua. Atualmente, conta com cerca de 900 associados pelo Brasil todo. Endereço eletrônico: www.cblj.com.br 56. Jornal do Nikkei (Nikkei Shinbun), 7 de outubro de 2005. 
na sede do CBLJ, juntamente com exposição de pintura, sebos de mangá, concurso de oratória e outras atividades afins. Segundo dados do CBLJ, no primeiro Concurso de Mangá e Animê, ocorrido em 2005, registraram-se 230 inscrições de trabalhos, conhecidos como yonkoma manga $a^{57}$ enviados por 43 escolas $^{58}$.

Dentre diversos empreendimentos de intercâmbio artístico, acadêmico, intelectual e de apoio ao ensino da língua japonesa promovidos pela Fundação Japão (FJ) ${ }^{59}$, a entidade seleciona e apóia projetos que possuam caráter pioneiro e criativo em todo o mundo. Em 2005, foi selecionada a proposta apresentada pelo Prof. Takashi Miura, que apresentou a Caravana de Karaokê. Um dos objetivos desse evento foi atingir jovens que tivessem interesse pela cultura pop japonesa. A Caravana percorreu diversas cidades brasileiras, como São Paulo, Rio de Janeiro, Brasília, Londrina, Porto Alegre, Belém, Manaus e Salvador, promovendo a integração de apreciadores e intérpretes amadores de música japonesa; também foram feitas demonstrações de como empregar a música como método de ensino da língua.

No relatório de metas de médio prazo da FJ, publicado no Japanese Ministry of Foreign Affairs ${ }^{60}$, sugere-se a ampliação de empreendimentos que incluam a cultura pop como instrumento importante para promover a compreensão sobre o Japão e o interesse por ele, bem como para melhorar o ensino da língua, com uso de diversas tecnologias de intermediação para levar em consideração a diversidade no perfil dos aprendizes e necessidade do estudo da língua.

\section{Aspectos do aprendizado}

Do ponto de vista do aprendizado da língua, sabemos que há um descompasso entre a linguagem utilizada em mangá e animê e aquela empregada nos livros didáti$\cos$, no que diz respeito aos registros lingüísticos (linguagem formal e informal, gêneros, de faixa etária, condição social, jargão profissional etc.). De fato, os gêneros didáticos privilegiam a memorização das 'formas lingǘsticas' de registro formal, como também há uma lista de sentenças-padrão e de vocabulário para a memorização. Enquanto isso, o mangá vale-se de recursos semióticos que funcionam como contextualização de enunciados, baseando-se em situações concretas de comunicação por meio de desenhos e ilustrações. Além disso, no que se refere à decodificação e leitura oral de caracteres ideográficos, o mangá emprega o recurso do furigana que funcionam como pontes entre a fase de alfabetização fonogramática a logogramática

57. Yonkoma manga é um tipo de mangá no qual o desenhista conta uma história em quatro cenários.

58. Jornal do Nikkei (Nikkei Shinbun), 2 de novembro de 2005.

59. Fundação Japão é uma organização vinculada ao Ministério das Relações Exteriores do Japão e foi estabelecida em 1972 e a sua inauguração em São Paulo aconteceu em 1975.

60. Endereço eletrônico do Ministry of Foreign Affairs: http://www.mofa.go.jp/ 
(ou kanji), que pode ser um fator de importância para a familiarização do aprendiz com uma língua que emprega escrita diferente da nossa, como também pode contribuir com a aprendizagem autônoma.

No caso do animê os recursos disponíveis são ainda mais dinâmicos, com movimentação e interação de personagens, além de contar com músicas e vozes. Essa diferença se contrapõe com o cenário de sala de aula tradicional, circunscrito muitas vezes à prática de escrever ou ler símbolos ideográficos. Fica uma dica para o professor que queira incrementar as aulas com ferramentas que proporcionem um aprendizado mais interativo, mais mediado pelos recursos da internet ainda pouco explorados.

\section{Considerações Finais}

Conforme já observado, dentre os itens da cultura pop japonesa difundidos pelo mundo, o animê ocupa um lugar de destaque pela facilidade de acesso na maior parte dos lares de todo o mundo. O contato com animê durante a infância e adolescência pode atuar como importante fonte inicial de informações sobre a história, cultura e modus vivendi dos japoneses, bem como servir de motivação para a escolha da carreira universitária ou de um curso livre de idiomas, conforme revelaram os resultados da enquête e da entrevista. O animê evidencia, do ponto de vista macro, uma porta de entrada para o estudo da língua japonesa aos não-descendentes, como também, aos descendentes que estão cada vez mais perdendo o contato com a língua no ambiente doméstico. Porém, do ponto de vista micro, fica para a instituição e para o professor, buscar recursos midiáticos de modo que contribua para um aprendizado eficaz, proporcionando progressos visíveis do ponto de vista da aprendizagem da língua. Não podemos substituir totalmente o livro didático pelo animê e/ou mangá, mas estes poderão ser explorados como recursos complementares ao livro principal, de modo que haja uma seleção prévia e planejada dos pontos a serem explorados como tópicos de aula.

Assim, em termos de elaboração de cursos em geral, é esperada uma revisão no conteúdo programático como também uma reflexão na metodologia ensino-aprendizagem de línguas, levando em conta o interesse do alunado, uma vez que a influência midiática continuará presente e cada vez mais acessível, eliminando fronteiras geográficas e minimizando diferenças sócio-culturais. 


\section{Referências bibliográficas}

ASHBY, Janet. "Manga culture ignites craze in media markets overseas" The Japan Times, 14/08/2003.

AOKI, Tamotsu; WANG, Ming; KONDÔ Seiichi. "Sekai ni 'Nihon no anime sedai' wo sodate yo" Chûô kôron, no. 10, 2005, p. 107-117.

ASÔ, Tarô. "Bunka gaikô no shinhassou - minasan no chikara wo motometeimasu" Palestra realizada na Dejitaru Hariuddo Daigaku em 28 de abril de 2006. Disponível em: http://www.mofa.go.jp/mofaj/press/enzetsu/18/easo 0428.html. Acesso em: 10 de maio de 2007.

"'BUNKA kôryû no heiwa kokka' Nihon no sôzô wo" Bunka gaikô no suishin ni kansuru kondankai hôkokusho. 11-07-2005. Disponível em: http:// www.kantei.go.jp/jp/singi/bunka/dai7/7sirvou1.pdf. Acesso em: 10 de maio de 2007.

CASTELLS, Manuel. A sociedade em rede. São Paulo: Paz e Terra, 1999.

ENDÔ, Yutaka. Gurôbaruka suru manga, anime, gêmu - saikôsei sareru 'Nihon bunka' Tôkyô daigaku bungaku bu, Kôdô bunka gaku shakai gaku senshû katei, 2001.

"ESPECIAL Japão: 40 anos na TV", Revista Kidmais, ano 2, no. 22, junho de 2000.

"FROM Niche to Mass: otaku bijinesu, sekai e hasshin", Newsweek (edição japonesa), 18/6/2003.

GRAVETT, Paul. Manga : Sixty Years of Japanese Comics. London: Laurence King Publishing Ltd, 2004.

"HARIUDDO wa Nihon ni muchû!", Newsweek (edição japonesa), 3/3/2004.

HELD, David \& MCGREW, Anthony. Prós e Contras da Globalização. Rio de Janeiro: Jorge Zahar, 2001.

HOOGVELT, Ankie. Globalization and the postcolonial world: the new political economy of development. Baltimore: The Johns Hopkins University Press, 2001.

"IS Japanese Style Taking Over The World?", BusinessWeek Online, 26/07/2004.

ITO, Kinko. "A History of Manga in the Context of Japanese Culture and Society", The Journal of Popular Culture, vol. 38, no. 3, 2005, pp. 456-475.

"INVASÃO de mangás", Made in Japan, no. 45, ano 4, junho de 2001.

JAPAN FOUNDATION. "Kaigai no nihongo kyôiku no genjô - nihongo kyôiku kikan chôsa 2003-nen" Disponível em: http://www.jpf.go.jp/j/japan j/oversea/ surveyold.html. Acesso em 10 de maio de 2007.

KINSELLA, Sharon. "Pro-establishment manga: pop-culture and the balance of power of Japan", Media, Culture \& Society, vol. 21, 1999, pp. 567-572.

LEONARD, Sean. "Progress against the law : Anime and fandom, with the key to the globalization of culture", International Journal of Cultural Studies, vol. 8, no. 3, 2005, pp. 281-305.

MANGÁS entre os livros mais vendidos dos EUA. UOL Teen, 13/09/2006. Disponível em: http://teen.uol.com.br/ultnot/ult742u3507.jhtm?action=print. Acesso em: 14 de setembro de 2006. 
MANION, Annie. Discovering Japan: anime and learning Japanese culture. Thesis Presented to the Faculty of Southern California. August 2005.

MASTRONARDI, Maria. "Adolescence and media", Journal of language and social psychology, vol. 22, no. 1, March 2003, pp. 83-93.

"NO mundo da fantasia", Veja, 29 de janeiro de 2003.

RELATÓRIO de Metas de Médio Prazo da Fundação Japão. Ministry of ForeIGN AfFAIRS, Disponível em: http://www.mofa.go.jp/mofaj/annai/shocho/hyouka/pdfs/ kikin_mokuhyo_2.pdf. Acesso em 4 de maio de 2007

SATO, Criastiane A. Japop: O poder da cultura pop japonesa. São Paulo, NSP Hakkosha, 2007.

SCHODT, Frederik. Manga! Manga! The world of Japanese comics. New York: Kodansha International. 1983.

SCHODT, Frederik. "Manga fans take their Japanese to another level" The Japan Times, 02/05/2006.

SETTON, Maria da Graça Jacintho. "A particularidade do processo de socialização contemporâneo", Tempo Social, v. 17, n. 2, novembro de 2005, pp. 335-350.

STEINBERG, Marc. "Immobile Sections and Trans-Series Movement: Astroboy and the Emergence of Anime", animation: an interdisciplinary journal, vol. 1, no. 2, 2006, pp. 190-206.

"VENDA de PCs no país deve encostar na de TVs neste ano", Folha de São Paulo, 3 de fevereiro de 2007.

"WATASHITACHI wa minna Nippon ni hamattemasu", Newsweek (edição japonesa), 5/4/2006.

YONEZAWA, Yoshihiro. "O culto mundial ao desenho animado japonês: Passado e presente do fenômeno", Nipponia, no. 27, 15 de dezembro de 2003, pp. 4-16. 